\title{
Evaluation of a single round polymerase chain reaction assay using dried blood spots for diagnosis of HIV-1 infection in infants in an African setting
}

Bhavna H Chohan ${ }^{1,2+}$, Sandra Emery ${ }^{3+}$, Dalton Wamalwa ${ }^{4}$, Grace John-Stewart ${ }^{5}$, Maxwel Majiwa ${ }^{4}$, Musa Ng'ayo $^{6}$, Steve Froggett ${ }^{3}$, Julie Overbaugh ${ }^{3^{*}}$

\begin{abstract}
Background: The aim of this study was to develop an economical 'in-house' single round polymerase chain reaction (PCR) assay using filter paper-dried blood spots (FP-DBS) for early infant HIV-1 diagnosis and to evaluate its performance in an African setting.

Methods: An 'in-house' single round PCR assay that targets conserved regions in the HIV-1 polymerase (pol) gene was validated for use with FP-DBS; first we validated this assay using FP-DBS spiked with cell standards of known HIV-1 copy numbers. Next, we validated the assay by testing the archived FP-DBS ( $N=115)$ from infants of known HIV-1 infection status. Subsequently this 'in-house' HIV-1 pol PCR FP-DBS assay was then established in Nairobi, Kenya for further evaluation on freshly collected FP-DBS $(N=186)$ from infants, and compared with findings from a reference laboratory using the Roche Amplicor ${ }^{\mathbb{B}}$ HIV-1 DNA Test, version 1.5 assay.

Results: The HIV-1 pol PCR FP-DBS assay could detect one HIV-1 proviral copy in 38.7\% of tests, 2 copies in $46.9 \%$ of tests, 5 copies in $72.5 \%$ of tests and 10 copies in $98.1 \%$ of tests performed with spiked samples. Using the archived FP-DBS samples from infants of known infection status, this assay was $92.8 \%$ sensitive and $98.3 \%$ specific for HIV-1 infant diagnosis. Using 186 FP-DBS collected from infants recently defined as HIV-1 positive using the commercially available Roche Amplicor v1.5 assay, 178 FP-DBS tested positive by this 'in-house' single-round HIV-1 pol PCR FP-DBS PCR assay. Upon subsequent retesting, the 8 infant FP-DBS samples that were discordant were confirmed as HIV-1 negative by both assays using a second blood sample.
\end{abstract}

Conclusions: HIV-1 was detected with high sensitivity and specificity using both archived and more recently collected samples. This suggests that this 'in-house' HIV-1 pol FP-DBS PCR assay can provide an alternative costeffective, reliable and rapid method for early detection of HIV-1 infection in infants.

\section{Background}

Although interventions to prevent mother-to-child transmission of HIV-1 infection are increasingly implemented as part of national guidelines, the prevalence of pediatric HIV-1 infection remains high in Africa. It is projected that about 1000 new pediatric cases occur daily worldwide, with $90 \%$ occurring in sub-Saharan

\footnotetext{
* Correspondence: joverbau@fhcrc.org

+ Contributed equally

${ }^{3}$ Division of Human Biology, Fred Hutchinson Cancer Research Center (1100 Fairview Ave N.), Seattle (98104), WA, USA Full list of author information is available at the end of the article
}

African countries [1,2]. Hence, an accurate economical and reliable early infant diagnosis of HIV-1 infection in Africa has become of paramount importance as such diagnosis can ensure that antiretroviral therapy is promptly provided for those in need. In addition infant HIV-1 diagnosis is the best measure for evaluation of mother-to-child transmission programs and can facilitate appropriate stratification of healthcare services [3].

Molecular methods such as polymerase chain reaction (PCR) assays are the most sensitive method for infant HIV-1 diagnosis [3-10] because passively acquired
C Biomed Central 
maternal antibodies in the infant complicates the use of conventional HIV-1 serologic diagnostic assays. Currently, a variety of validated commercially available and 'in-house' PCR-based methods that detect HIV-1 nucleic acids are available [3,5-8,10-13]. Many of these methods have been adapted for HIV-1 diagnosis using either whole blood, or dried blood spots collected on filter papers (FP-DBS), which are more convenient for collection, transport and storage. However many of these commercial PCR-based assays on FP-DBS for early HIV1 infant diagnosis are expensive (in the range of $\$ 20-\$ 50$ per assay), and therefore beyond the reach of the majority of the population that resides in low-resource settings where the epidemic is prevalent [3]. Hence, there has been an urgent need for cheaper and reliable assays for early HIV-1 infant diagnosis.

Previously, our laboratory evaluated an 'in-house' PCR assay for HIV diagnosis that relied on a two round, nested PCR amplification of the HIV-1-gag sequences from FP-DBS [4]. The PCR results using FP-DBS showed $100 \%$ specificity, and $96 \%$ sensitivity (based on quadruplicate testing) compared to results with blood mononuclear cells collected from paired venous blood [4]. However, an assay that relies on two rounds of PCR can be challenging in laboratories that do not have optimal facilities for minimizing PCR contamination.

Here we describe an inexpensive single round PCR that requires minimal nucleic acid manipulation and compare its performance with the earlier HIV-1-gag PCR assay and the commercial Roche qualitative HIV Amplicor ${ }^{\circledR}$ DNA PCR, version 1.5 assay, which is currently the assay with extensive validation in Africa [3].

\section{Methods}

\section{PCR methods}

The PCR method described here was a modification of a previously described real-time PCR assay that targets the HIV polymerase $(p o l)$ gene $[14,15]$. Minor changes were made by shifting the primers to minimize non-specific amplification. The primers used were forward primer pol 151 5'TACAGTGCAGGGGAAAGAATAATAG3' (corresponds to positions 4809 - 4833 in $\mathrm{HXB2}$ ) and the reverse primer pol 40 5'CTACTGCCCCTTCACCT TTCC3' (position 4954- 4974 in HXB2). The PCR reaction mixture contained $150 \mu \mathrm{mol} / \mathrm{L}$ of $\mathrm{MgCl}_{2}, 200$ $\mu \mathrm{mol} / \mathrm{L}$ of $\mathrm{dNTP}, 1 \mu \mathrm{mol} / \mathrm{L}$ of each primer, $1.5 \mathrm{U}$ of $\mathrm{ABI}$ AmpliTaq Gold Polymerase and appropriate buffer mix (Applied Biosystems), 0.1\% of Bovine Serum Albumin, and $2 \mu \mathrm{l}$ of the DNA template. The cycling parameters used were $50^{\circ} \mathrm{C}$ for $2 \mathrm{~min} ; 95^{\circ} \mathrm{C}$ for $10 \mathrm{~min}, 1$ cycle; $95^{\circ}$ $\mathrm{C}$ for $15 \mathrm{~s}$ and $60^{\circ} \mathrm{C}$ for 42 cycles. The expected product is $166 \mathrm{bp}$, which was visualized by gel electrophoresis through $2 \%$ agarose and ethidium bromide staining. We refer to this assay as the HIV-1 pol PCR FP-DBS assay.

\section{Extraction of nucleic acids from FP-DBS}

The nucleic acids were extracted from the FP-DBS by two different methods, depending on the assay performed on the sample.

For the regular 'in-house' pol and gag PCR FP-DBS assay, a lysate was prepared by lysing the blood sample from the FP-DBS, using an ethanol-flamed $8 \mathrm{~mm}$ hole punch to detach a blood spot, which samples about one quarter of the total blood spot. Nucleic acids from the DBS spot were extracted using a quick lysis approach, that required addition of $100 \mu \mathrm{l}$ lysis buffer $(10 \mathrm{mM}$ Tris- $\mathrm{HCl}\{\mathrm{pH} 8.3\}, 50 \mathrm{mM} \mathrm{KCl}, 100 \mu \mathrm{g}$ of gelatin, $0.45 \%$ Tween 20, $0.45 \%$ Nonidet P-40, $60 \mu \mathrm{g}$ of proteinase $\mathrm{K}$ per $\mathrm{ml}$ ), and lysing for 90 minutes at $56^{\circ} \mathrm{C}$, followed by incubation at $95^{\circ} \mathrm{C}$ for 20 minutes to inactivate the proteinase $\mathrm{K}$, all performed in a single tube to minimize handling [4]. Each tube with lysed sample was then spun at $1000 \mathrm{~g}$ for 7 minutes to force the filter paper disc and other debris to the bottom of the tube and supernatants containing lysed samples were either immediately used in PCR or stored at $-20^{\circ} \mathrm{C}$ for later use. A volume of $2 \mu \mathrm{l}$ of lysate from FP-DBS was used in $50 \mu \mathrm{l}$ PCR reaction for all studies unless indicated. To validate the assay, the amplified product from one PCR was verified by sequence analysis as being the desired sequence (not shown).

For testing of samples by HIV-1 pol real-time PCR to verify HIV-1 copy numbers, nucleic acids were extracted from the FP-DBS using standard Qiagen DNA extraction kit.

\section{FP-DBS samples}

For initial studies FP-DBSs with known quantities of HIV-infected cells were made by spotting approximately $50 \mu \mathrm{l}$ HIV negative blood along with ACH2 cells, which contain a single integrated copy of HIV-1 proviral DNA per cell [16,17], on S\&S 903 filter paper (Schleicher \& Schuell, Keene, NH). HIV negative blood spots were made from drops of blood with no anticoagulant mimicking blood collected from infant heel prick, and allowed to air-dry overnight. HIV-1 infected ACH2 cells were counted on a hemacytometer and the cells were diluted in sterile PBS to obtain the final expected 10, 5, 2 or 1 infected cells per $2 \mu$ of eluate, which was the volume used for each PCR reaction. The quantified cells in PBS $(10 \mu \mathrm{l})$ were then spotted onto $8 \mathrm{~mm}$ punch of the FP-DBS prepared from HIV-negative blood, allowed to soak in and air-dry. In this case, the total number of cells changed very little from sample to sample, since the added ACH2 cells would represent a very small fraction of the total cells in a dried blood spot. To confirm the quantity of viral copies in the diluted HIV-1 infected ACH-2 cell suspension, at a later date, the DNA was extracted using the Qiagen DNA extraction kit, and 
HIV copy number was quantified using HIV-1 pol realtime PCR $[14,15]$.

Archived FP-DBS, collected on S\&S 903 filter paper (Schleicher \& Schuell, Keene, NH) from 115 infants from Nairobi, Kenya of known infection status (56 HIV1 positive and 59 HIV-1 negative), were collected, airdried and shipped to Seattle. These archived FP-DBS that had been stored at ambient room temperature for 3 to 7 years in envelopes, in the Seattle laboratory with no desiccant were tested with the HIV-1 pol PCR FPDBS assay. The operator was blinded to the infection status of the infant when the HIV-1 pol PCR FP-DBS assay was performed.

Subsequently, FP-DBS $(\mathrm{N}=186)$ from more recent samples collected on S\&S 903 filter paper (Schleicher \& Schuell, Keene, NH) between the years 2007 to 2009 from infants aged $<1$ year were tested on site in Nairobi, Kenya. The FP-DBS were prepared by spotting $50 \mu \mathrm{l}$ of whole blood in EDTA, air-dried overnight and stored in zip-lock bags with a desiccant at ambient room temperatures before use, which was within one month of storage.

The infant blood samples for the FP-DBS were obtained as part of NIH-funded research studies with consent from the mothers or the caregivers of the infant, and tested for HIV infection with ethical approval from the Institutional Review board at University of Washington (approval \# 98-7407-A) and Fred Hutchinson Cancer Research Center, USA (\# 6341), and Kenyatta National Hospital, Kenya (approval \# P4/01/2006).

\section{Results}

In initial studies, various amounts of lysate were tested in the HIV-1 pol FP-DBS PCR to determine if there was inhibition due to heme and other factors in the lysed sample. As we had seen previously with the nested HIV1 gag FP-DBS PCR assay [4], addition of $5 \mu \mathrm{l}$ and greater of the FP-DBS lysate into a $50 \mu \mathrm{l}$ PCR resulted in some inhibition of the reaction (not shown). In other studies, we found this was true for blood collected in no anticoagulant or with EDTA or ACD; the inhibition was even more pronounced using blood collected in heparin (data not shown). For this reason, we used $2 \mu \mathrm{l}$ of lysate from FP-DBS for the HIV-1 pol FP-DBS PCR from FP-DBS prepared by spotting whole blood or blood collected in EDTA.

\section{Performance of HIV-1 pol PCR FP-DBS assay with spiked FP-DBS prepared from known HIV-1 copy numbers}

To examine the ability of this 'in-house' HIV-1 pol PCR assay to detect the range of HIV-1 copy numbers from FP-DBS samples, defined quantities of ACH-2 cells were applied to FP-DBS. For this purpose, ACH2 cells were counted two different times (A \& B) on two separate days (D1 \& D2), as shown in Table 1. The total amount added to the FP-DBS was calculated so that $2 \mu \mathrm{l}$ of the final lysate would be expected to have 10, 5, 2 and 1 HIV-1 proviral copies. To verify these numbers in parallel, extracted DNA from an aliquot of each tube of manually counted $\mathrm{ACH} 2$ cells was tested in triplicate with the HIV-1 pol real-time PCR assay [14,15], and the results from this assay gave an expected HIV-1 copy number that was within 2 -fold of that predicted by cell count in 14 of 16 cases; the 2 discrepant cases were at the lowest cell count (Table 1). A total of 40 PCRs were performed on lysate from each cell preparation: in each case, four FP-DBSs were prepared and 10 HIV-1 pol PCRs were performed from every FP-DBS lysate (Table 1).

The results of HIV-1 pol PCR FP-DBS assay showed that one HIV-1 proviral copy was detectable in $38.7 \%$ of tests (160 total tests), 2 copies in $46.9 \%$ of tests, 5 copies in $72.5 \%$ of tests, and 10 copies in $98.1 \%$ of tests, as expected based on Poisson distribution (Table 1). This experiment was repeated a second time on two separate days with similar results (data not shown). Comparable results were also obtained in smaller studies using FPDBS prepared from PBMCs infected with different HIV subtypes (A, C and D; data not shown), which is consistent with our previous studies showing that with the same primers, HIV-1 pol PCR assay in the real-time format can detect these HIV subtypes [15]. Overall, these data with unpurified cell lysates using HIV-1 pol PCR FP-DBS assay compared favourably with results of the real-time HIV-1 pol PCR assay where nucleic acid was prepared using a Qiagen purification method prior to PCR [14]. These data suggest that the HIV-1 pol PCR FP-DBS assay is able to reliably detect as low as a single copy of HIV provirus from a FP-DBS with minimal nucleic acid purification.

\section{pol PCR FP-DBS assay on stored samples from infants of known HIV-1 infection status}

We next evaluated the HIV-1 pol PCR FP-DBS assay using stored FP-DBS from infants of known infection status, as defined by prior testing of two sequential samples with the HIV-1 gag PCR assay $[4,18]$. These FPDBS had been prepared by spotting whole blood on the filter paper, air-dried and stored at ambient room temperature for several years. One hundred and fifteen FPDBS (56 HIV-1 positive and 59 HIV-1 negative) were tested with the operator blinded to the infection status. The lysate was tested in parallel with the two round, nested HIV-1 gag PCR that was used previously and the single round HIV-1 pol PCR FP-DBS assay. The nested HIV-1 gag PCR that amplified a 142bp of fragment, nearly the same size fragment as the single round HIV-1 pol PCR FP-DBS assay served as a control for the 
Table 1 Summary of HIV-1 pol FP-DBS PCR assay performed on DBS spiked with low copy number ACH2 cells

\begin{tabular}{|c|c|c|c|c|}
\hline $\begin{array}{l}\text { Cell count } \\
\text { Copies } / \mathrm{ml}\end{array}$ & $\begin{array}{c}\text { pol real-time copies/rx } \\
\text { (on } \mathrm{ACH} 2 \text { used to spike) } \\
\text { avg } 3 \text { tests }\end{array}$ & $\begin{array}{l}\text { No. positive (\%) } \\
\text { qualitative PCR } \\
\text { on DBS lysate } \\
\end{array}$ & Avg $\%$ D1 or D2 & $\begin{array}{l}\text { Avg \% both days } \\
\text { (D1 and D2) }\end{array}$ \\
\hline 10(A)D1 & 11.4 & $40(100)$ & 98.7 & 98.1 \\
\hline 10(B)D1 & 6.5 & $39(97.5)$ & & \\
\hline 10(A)D2 & 17.5 & $38(95)$ & 97.5 & \\
\hline 10(B)D2 & 12.5 & $40(100)$ & & \\
\hline $5(\mathrm{~A}) \mathrm{D} 1$ & 12.6 & $26(65)$ & 72.5 & \\
\hline $5(\mathrm{~B}) \mathrm{D} 1$ & 4.95 & $32(80)$ & & 72.5 \\
\hline $5(A) D 2$ & 3.5 & $25(62.5)$ & 72.5 & \\
\hline $5(B) D 2$ & 3.6 & $33(82.5)$ & & \\
\hline 2(A)D1 & 1.1 & $27(67.5)$ & 75 & 46.9 \\
\hline 2(B)D1 & 3.05 & $33(82.5)$ & & \\
\hline 2(A)D2 & 1.5 & $11(27.5)$ & 18.8 & \\
\hline 2(B)D2 & 1.3 & $4(10)$ & & \\
\hline $1(\mathrm{~A}) \mathrm{D} 1$ & 1.6 & $18(45)$ & 56.2 & 38.7 \\
\hline 1(B)D1 & 0.8 & $27(67.5)$ & & \\
\hline $1(\mathrm{~A}) \mathrm{D} 2$ & 0.1 & $9(22.5)$ & 21.2 & \\
\hline 1(B)D2 & 3.3 & $8(20)$ & & \\
\hline
\end{tabular}

A total of 40 HIV-1 pol PCR assays were performed on FP-DBS spiked in duplicate (A and B) with known copies of HIV-1 in ACH-2 cells (manually counted and quantified by HIV-1 pol real-time PCR assay done) on two different days (D1 and D2). The results of the HIV-1 pol PCR assay are indicated as an average percentage of HIV-1 proviral copies detected from the spiked FP-DBS.

integrity of the FP-DBS samples, which had been stored at ambient room temperature for several years.

The repeat testing of the stored FP-DBS from these infants with the original HIV-1 gag PCR showed 95.6\% agreement with the prior testing that established infection status, suggesting that the long-term storage had not significantly compromised the samples. These same samples were tested with the HIV-1 pol PCR FP-DBS assay. The sensitivity and specificity of the HIV-1 pol PCR assay in relation to the known HIV-1 infection status of the infants was $92.8 \%$ and $98.3 \%$ respectively (Table 2).

\section{Comparison of pol PCR FP-DBS assay with commercial DBS-FP assay}

The assay was transferred from the Seattle-based laboratory to a newly established molecular virology laboratory at the University of Nairobi. This laboratory included a PCR set-up room that had established standard practices to minimize the potential for introduction of PCR product, plasmid and other possible PCR contaminants. In this laboratory, we tested follow-up FP-DBS samples prepared from whole blood in EDTA collected from infants that were initially reported as HIV-1 positive using the Roche Amplicor v1.5 assay at the National Reference Laboratory for Early Infant Diagnosis testing at Kenya Medical Research Institute or at Kenyatta National Hospital, in Nairobi, Kenya, typically within the prior month. For this confirmatory HIV-1 testing, the infant was rebled and a fresh FP-DBS was prepared from $50 \mu \mathrm{l}$ of whole blood, air-dried and lysed for PCR analysis. The lysate was then tested in quadruplicate PCRs using both the HIV-1 gag and pol PCRs (see gel picture Figure 1).

As a control, we also included randomly within the test runs, 25 FP-DBS collected from HIV-1 seronegative

Table 2 A $2 \times 2$ table for performance of HIV-1 pol FP-DBS PCR assay on archived FP-DBS samples

\begin{tabular}{ccccc}
\hline & & \multicolumn{3}{c}{ KNOWN HIV-1 STATUS } \\
\cline { 2 - 5 } pol PCR HIV-1 results & Positive & 52 & 1 & 53 \\
\cline { 2 - 5 } & Negative & 4 & 58 & 62 \\
\hline & TOTAL & 56 & 59 & 115 \\
\hline
\end{tabular}

Samples were obtained from infants of known HIV-1 infection status (56 HIV-1 positive and 59 HIV-1 negative). The sensitivity of HIV-1 pol PCR FP-DBS assay on archived FP-DBS was $92.8 \%$ and specificity of $98.3 \%$. 


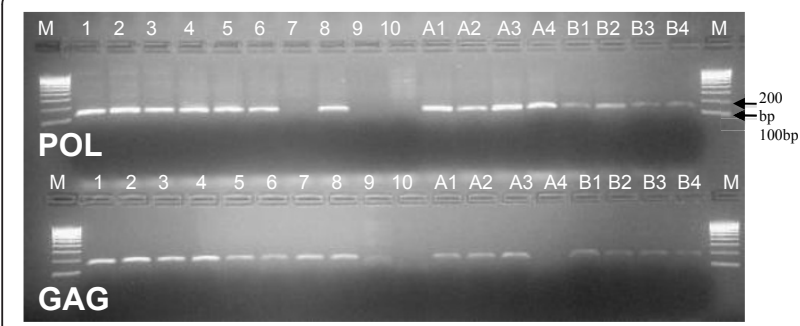

Figure $1 \mathrm{Gel}$ picture of amplified products using 'in-house' HIV-1 gag and pol FP-DBS PCR assay. Gel picture of the HIV-1 pol (top panel - 160bp) and gag (lower panel - 152bp) PCR products. Lanes labeled from 1- 10 are PCR products from the ACH copy number controls: 1-2 are 100 HIV copies; 3-4 are 10 copies; 4-8 are 2 copies; 9 and 10 are negative controls using DNA from an uninfected T cell cell-line and water as the PCR template, respectively. PCR results from two samples of DBS-FP from infants who tested positive with the Roche Amplicor assay are labeled as A1-A4 and B1-B4, with 1-4 indicating quadruplicate tests. Based on the results show, both infants would be defined a HIV-1 DNA PCR positive according to testing algorithm for the' in-house' gag and pol FP-DBS FP PCR. The first and last lane in the gel picture (labeled $\mathrm{M})$ in both the panels is the molecular weight marker - Hyperladder IV

adults, as defined by two parallel rapid HIV-1 serological assays. The test operator was blinded to HIV-1 serostatus of the control samples and upon testing all the quadruplicate PCR tests on the samples, both for gag and pol products were negative.

Of the $186 \mathrm{HIV}-1$ positive samples from the infants that were defined as positive with Roche Amplicor ${ }^{\circledR}$ HIV-1 DNA assay version 1.5, 178 samples were confirmed as positive by HIV-1 pol PCR FP-DBS assay (Figure 2). Of the 8 samples that were negative by both HIV-1 pol and gag PCRs, the infants were re-bled and re-tested using all the tests, the Roche Amplicor ${ }^{B}$ HIV-1 DNA v1.5 assay (at the reference lab) and the HIV-1 gag and pol PCR FP-DBS assay. Upon retesting all of the 8 infants were identified as HIV-1 negative by all assays, suggesting the initial results using the commercial Roche Amplicor $^{\circledR}$ assay were false positive results. However, we could not determine whether the initial results of the Roche Amplicor ${ }^{\circledR}$ assay for the 8 infants were the result of false positive tests or whether sample mix-up could have contributed to these results. The HIV-gag PCR showed only $87 \%$ sensitivity (155 of 178 positives) compared to both the Roche Amplicor ${ }^{\circledR}$ and HIV-1 pol PCR FP-DBS assay.

The infants were all under the age of 12 months. Most (46\%) were between 3 and 6 months, but we also sampled younger infants $(25 \%<3$ months $)$ and older infants $(29 \%>6$ months), as shown on Table 3 . Of the 178 HIV-1 positive infants as determined by DNA PCR on FP-DBS using all the 3 methods (Roche Amplicor ${ }^{\circledR}$ and 'in-house' gag and pol assay), 110 infants had HIV-1

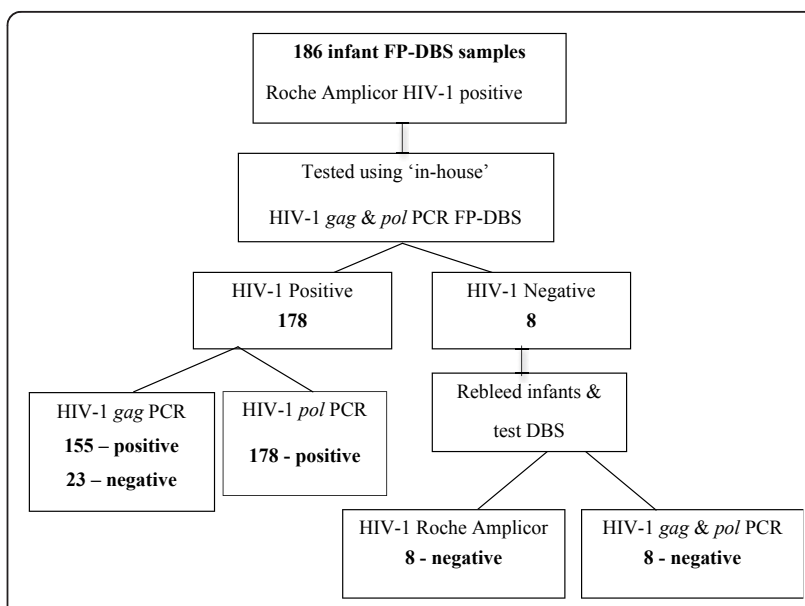

Figure 2 Experimental approach for performance of HIV-1 gag and pol FP-DBS PCR assay for detection of HIV-1 infection from FP-DBS obtained from HIV-1 positive infants as defined by Roche Amplicor v1.5 assay. 186 recently collected FP-DBS that were determined in the prior $\sim$ month to be HIV-1 positive by Roche Amplicor V1.5 assay were tested by HIV-1 gag and pol PCR assays. Of these 178 FP-DBS from the infants were identified as HIV1 positive. Retesting of subsequent blood samples from the 8 discordant infants showed that they were HIV-1 negative. Thus, the sensitivity of HIV-1 pol PCR assay was found to be $100 \%$ (178 of 178) for detection of confirmed HIV-1 positive infants from FP-DBS.

subtype data available based on pol sequence. The majority $(69 \%)$ of the infants were identified as infected with HIV-1 subtype A, and others with subtype D (23\%), subtype $C(7 \%)$ and intersubtype recombinant AD (1\%) (Table 4). This is very similar to the subtype distribution in Nairobi [19].

Overall, from the 178 samples confirmed positive with Roche Amplicor ${ }^{\circledR}$ assay, all were positive by HIV-1 pol PCR, indicating that the sensitivity and specificity of the HIV-1 pol PCR assay was $100 \%$ in this study. As this is based on using data from 4 HIV-1 pol PCR tests to detection infection, we also examined the sensitivity if we considered the results from just the first (single test), the first two (duplicate) or the first 3 (triplicate) HIV-1 pol PCR tests. Based on our results of HIV-1 pol PCR assay the likelihood of missing true positives if we had performed the assay singly would be $14.6 \%$ (26 of 178),

Table 3 Age demographics of infants tested for HIV-1 DNA PCR from freshly collected DBS samples in Nairobi, Kenya

\begin{tabular}{lccccc}
\hline & \multicolumn{5}{c}{ Age of infants (months) } \\
\cline { 2 - 6 } & $<\mathbf{3}$ & $\mathbf{3}$ to $<\mathbf{6}$ & $\mathbf{6}$ to $<\mathbf{9}$ & $\mathbf{9}$ to $<\mathbf{1 2}$ & Total \\
\hline No. infants & 47 & 85 & 39 & 15 & 186 \\
& $25.3 \%$ & $45.7 \%$ & $21.0 \%$ & $8.0 \%$ & \\
\hline Mean Age & 4.6 months & & & \\
Range & 3 wks -11.5 months & & & \\
\hline
\end{tabular}


Table 4 HIV-1 subtypes in infants who tested positive with the HIV-1 pol FP-DBS PCR assay in Nairobi, Kenya

\begin{tabular}{ccccc}
\hline \multicolumn{5}{c}{ HIV-1 subtypes } \\
\hline A & D & C & AD recomb & Total \\
\hline 76 & 25 & 8 & 1 & 110 \\
$69 \%$ & $23 \%$ & $7 \%$ & $1 \%$ & \\
\hline
\end{tabular}

Note: HIV-1 subtypes based on 667bp polymerase genome HIV- 1 subtypes available for only 110 of the 178 HIV- 1 positive DBS-FP from infants in the Nairobi study.

in duplicate testing would be $6.7 \%(12 / 178)$, in triplicate testing would be approximately $0.6 \%(1 / 178)$, and on quadruplicate testing would be none.

\section{Discussion}

In summary, we describe here a sensitive HIV-1 pol PCR FP-DBS assay for detection of infant infection. The advantages of this assay include the fact that it requires minimal manipulation of the sample compared to assays that rely on extraction of nucleic acids and nested PCR methods. This method can detect a single copy of HIV provirus and has been validated on HIV-1 sequences of multiple subtypes.

The HIV-1 pol PCR FP-DBS assay was compared to results from historical studies in Seattle as well as samples from infants who recently tested positive by the Roche Amplicor ${ }^{\circledR}$ HIV-1 DNA Test, version 1.5 assay in Nairobi. The sensitivity and specificity of the HIV-1 pol PCR FPDBS assay was $>90 \%$ on archived samples stored for more than 3 years at room temperature. The combined sensitivity of the HIV-1 pol PCR FP-DB assay using the archived $(\mathrm{N}=56$ positive $)$ and recent samples $(\mathrm{N}=178$ positive $)$ was $98.3 \%$ (Table 5). These comparisons are based on quadruplicate testing, which maximizes detection of low HIV copies in a sample. Using this approach, we detected $100 \%$ of confirmed positive samples from infants recently identified as HIV positive by the Roche Amplicor ${ }^{\circledR}$ HIV-1 DNA assay. Based on initial field site testing of FP-DBS from 178 HIV positive infants, this HIV-1 pol PCR FP-

Table 5 A $2 \times 2$ table for performance of HIV-1 pol FP-DBS PCR assay on all FP-DBS

\begin{tabular}{lcccc}
\hline & & \multicolumn{3}{c}{ KNOWN HIV-1 STATUS } \\
\cline { 2 - 5 } & & Positive & Negative & TOTAL \\
\hline pol PCR HIV-1 results & Positive & 230 & 1 & 231 \\
\cline { 2 - 5 } & Negative & 4 & 91 & 95 \\
\hline & TOTAL & $* 234$ & $\$ 92$ & 326 \\
\hline
\end{tabular}

A total of 115 archived and 211 current FP-DBS samples of known HIV-1 infection status were tested. Overall the sensitivity of HIV-1 pol PCR FP-DBS assay on all FP-DBS samples (archived and recent samples) was $98.3 \%$ and specificity of $98.9 \%$.

* a total of 56 archived FP-DBS samples and 178 recent FP-DBS samples obtained from infants.

$\$$ a total of 59 archived and 33 recent FP-DBS samples (8 obtained from infants and 25 from adults).
DBS assay with a single, duplicate or triplicate PCR testing would be predicted to detected $~ 85 \%, 93 \%$ and $99 \%$ of HIV-1 positive samples, respectively.

The HIV-1 pol PCR FP-DBS assay samples a lower total volume of blood than the commercial assays that go through a purification step to remove inhibitors, which lengthens and complicates these assays. Thus, while the Roche Amplicor ${ }^{\circledR}$ HIV-1 DNA assay typically tests for HIV in $\sim 12.5 \mu \mathrm{l}$ of blood eluate (assuming processing a $50 \mu \mathrm{l}$ blood spot by adding $200 \mu \mathrm{l}$ lysate and testing $50 \mu \mathrm{l}$ ), the HIV-1 pol PCR FP-DBS assay only tests $0.2-0.3 \mu$ l blood eluate per PCR (in this assay only $\sim$ a quarter of the blood spot is sampled, $\sim 10-12 \mu \mathrm{l}$ of blood); this is lysed in $100 \mu \mathrm{l}$ and $2 \mu \mathrm{l}$ of lysate is used per PCR. However, this lower blood volume used in the HIV-1 pol PCR FP-DBS assay should be adequate to sample HIV-infected cells in an infant sample. Infant blood contains an estimated 75.4 \pm 104.3 HIV proviral copies per 1000 PBMC [20]. Assuming that $1 \mu \mathrm{l}$ of blood contains 1 million total cells, of which 5000 are PBMCs [21], then there are 1000 PBMC sampled in each PCR. Thus, each PCR that includes $0.2 \mu \mathrm{l}$ of infant blood typically contains multiple HIV copies that can be detected in this assay that should be amplified with this single HIV-1 copy detection PCR method.

Even when performed in quadruplicate, this qualitative DNA assay is economical and costs just a few dollars per patient, compared to some of the commercial assays that are nearly 5 to 10 times more expensive ( 20-50 US\$). While quadruplicate testing may provide optimal sensitivity, this assay may also be highly sensitive and specific when PCRs are performed in duplicate or triplicate. However, quadruplicate testing may increase the ability of this assay to detect infants that are destined to become slow progressors, who are estimated to have lower HIV proviral copy numbers $(11.8+18.8$ HIV copies/1000 PBMC; [20]). Laboratories that adapt this assay may wish to compare the performance of quadruplicate testing versus using fewer replicate tests to determine the number of PCR tests that are optimal to suit their needs.

Importantly, when transferred to a new laboratory in Nairobi for on-site testing in a setting that applied stringent measures to minimize PCR contamination, the assay showed very high sensitivity and specificity compared to the results of commercial assays from established reference laboratories in the region. Of course, the performance of this assay in other settings may vary depending on the established protocols and expertise of the laboratory, as is true with the use of any PCR-based assays-either 'in-house' or commercial. One limitation of the study results described here is that they focused primarily on samples from infants recently detected as HIV-1 positive by the Roche Amplicor ${ }^{\circledR}$ HIV-1 DNA Test. Further studies of infants born to HIV-positive 
mothers that are not pre-screened in this manner will be needed to more precisely define the sensitivity and specificity of this assay in a clinical setting in real time. In this case, it will be important to not only verify the findings with a second assay, but also to test a follow-up sample from each infant because other assays also have limitations in their performance, such as the false-positive results using the Roche Amplicor ${ }^{\circledR}$ HIV-1 DNA Test described here. While further testing by other laboratories will be useful for validating the performance of this assay, these findings suggest that the HIV-1 pol PCR FP-DBS assay provides a reliable and rapid method, and is an economical assay for early detection of HIV-1 infection in infants.

\section{Conclusions}

There is an urgent need for an economical and reliable assay for early HIV-1 infant diagnosis, especially for low-resource countries. This study has validated an economical 'in-house' HIV-1 pol PCR FP-DBS assay that is highly sensitive and specific when compared to a commercial Roche Amplicor ${ }^{\circledR}$ v1.5 FP-DBS assay. This study highlights the need for potential adaptation of this qualitative DNA-based assay in development of a rapid point-of care diagnostics assay for early infant HIV-1 diagnosis. This single round pol PCR FP-DBS can therefore be a useful tool for early infant HIV-1 diagnosis in Africa especially where the HIV epidemic prevails and resources are limited.

\begin{abstract}
Acknowledgements
We acknowledge the samples provided by the infants enrolled in a clinical trial at the comprehensive care clinic at Kenyatta National Hospital, Nairobi, Kenya.

We highly appreciate the efforts of Dr. Dara Lehman,who helped advise during the transfer of the technology to Kenya, and Dr. Sarah Benki, who helped with some of the analyses.

This work was supported by NIH R01 grants HD023412 and Al076105. BC support was in part by an advanced in country scholar award from the Fogarty (D43-TW000007). We also acknowledge Center of AIDS Research (CFAR) of University of Washington/Fred Hutchinson Cancer Research Center, Seattle, Washington, for support in the construction of the field research laboratory where the work was done in Nairobi, Kenya.
\end{abstract}

\section{Author details}

'Department of Medical Microbiology, University of Nairobi - College of Health Sciences (off Ngong Road), Nairobi (Box 19767-00202), Kenya. ${ }^{2}$ Department of Medicine, Division of Allergy and Infectious Diseases, University of Washington (Pacific Street), Seattle (98104), WA, USA. ${ }^{3}$ Division of Human Biology, Fred Hutchinson Cancer Research Center (1100 Fairview Ave N.), Seattle (98104), WA, USA. ${ }^{4}$ Department of Paediatrics, University of Nairobi - College of Health Sciences (off Ngong Road), Nairobi (Box 1976700202), Kenya. ${ }^{5}$ Department of Epidemiology, University of Washington (325 9thAve), Seattle (98104), WA, USA. ${ }^{6}$ Center for Microbiology Research, Kenya Medical Research Institute (Hospital Street), Nairobi (Box 19464-00202), Kenya.

\section{Authors' contributions}

$\mathrm{BHC}$ helped design aspects of the study, validated and performed assays, analyzed the data and helped draft the manuscript. SE validated and performed assays, and provided input into the manuscript. MM and MN participated in the study by performing the assay on the samples in the field. SF was helpful in setting up the molecular virology laboratory in the field and assisting in transferring the technology and training staff on the methods. GJ-S and DW as Principal Investigators of the research project from which clinical samples were obtained, provided the samples in the field for evaluation of the assay and gave input into the study design. JO conceived the idea and led the study design, implementation of the program and drafting and editing of the manuscript. All authors contributed to the data analysis and read and approved the final manuscript.

\section{Competing interests}

The authors declare that they have no competing interests.

Received: 3 June 2010 Accepted: 18 February 2011

Published: 18 February 2011

\section{References}

1. Global Summary of HIV AIDS epidemic. UNAIDS.

2. WHO: Paediatric HIV and treatment of children living with HIV. 2008.

3. Stevens W, Sherman G, Downing R, Parsons LM, Ou CY, Crowley S, GershyDamet GM, Fransen K, Bulterys M, Lu L, et al: Role of the Laboratory in Ensuring Global Access to ARV Treatment for HIV-Infected Children: Consensus Statement on the Performance of Laboratory Assays for Early Infant Diagnosis. Open AIDS J 2008, 2:17-25

4. Panteleeff DD, John G, Nduati R, Mbori-Ngacha D, Richardson B, Kreiss J, Overbaugh J: Rapid method for screening dried blood samples on filter paper for human immunodeficiency virus type 1 DNA. J Clin Microbiol 1999, 37:350-353.

5. Bremer JW, Lew JF, Cooper E, Hillyer GV, Pitt J, Handelsman E, Brambilla D, Moye J, Hoff R: Diagnosis of infection with human immunodeficiency virus type 1 by a DNA polymerase chain reaction assay among infants enrolled in the Women and Infants' Transmission Study. J Pediatr 1996, 129:198-207.

6. Fischer A, Lejczak C, Lambert C, Servais J, Makombe N, Rusine J, Staub T, Hemmer R, Schneider F, Schmit JC, Arendt V: Simple DNA extraction method for dried blood spots and comparison of two PCR assays for diagnosis of vertical human immunodeficiency virus type 1 transmission in Rwanda. J Clin Microbiol 2004, 42:16-20.

7. Nyambi PN, Fransen K, De Beenhouwer H, Chomba EN, Temmerman M, Ndinya-Achola JO, Piot P, van der Groen G: Detection of human immunodeficiency virus type 1 (HIV-1) in heel prick blood on filter paper from children born to HIV-1-seropositive mothers. J Clin Microbiol 1994, 32:2858-2860.

8. Sherman GG, Cooper PA, Coovadia AH, Puren AJ, Jones SA, Mokhachane M, Bolton KD: Polymerase chain reaction for diagnosis of human immunodeficiency virus infection in infancy in low resource settings. Pediatr Infect Dis J 2005, 24:993-997.

9. Sherman GG, Stevens G, Jones SA, Horsfield P, Stevens WS: Dried blood spots improve access to HIV diagnosis and care for infants in lowresource settings. J Acquir Immune Defic Syndr 2005, 38:615-617.

10. Walter J, Kuhn L, Semrau K, Decker DW, Sinkala M, Kankasa C, Thea DM, Bulterys M, Ou CY, Aldrovandi GM: Detection of low levels of human immunodeficiency virus (HIV) may be critical for early diagnosis of pediatric HIV infection by use of dried blood spots. J Clin Microbiol 2009, 47:2989-2991.

11. Dunn DT, Brandt CD, Krivine A, Cassol SA, Roques P, Borkowsky W, De Rossi A, Denamur E, Ehrnst A, Loveday C: The sensitivity of HIV-1 DNA polymerase chain reaction in the neonatal period and the relative contributions of intra-uterine and intra-partum transmission. Aids 1995, 9:F7-11.

12. Patton JC, Akkers E, Coovadia AH, Meyers TM, Stevens WS, Sherman GG: Evaluation of dried whole blood spots obtained by heel or finger stick as an alternative to venous blood for diagnosis of human immunodeficiency virus type 1 infection in vertically exposed infants in the routine diagnostic laboratory. Clin Vaccine Immunol 2007, 14:201-203.

13. Waters L, Kambugu A, Tibenderana H, Meya D, John L, Mandalia S, Nabankema M, Namugga I, Quinn TC, Gazzard B, et al: Evaluation of filter paper transfer of whole-blood and plasma samples for quantifying HIV RNA in subjects on antiretroviral therapy in Uganda. J Acquir Immune Defic Syndr 2007, 46:590-593.

14. Benki S, McClelland RS, Emery S, Baeten JM, Richardson BA, Lavreys L, Mandaliya K, Overbaugh J: Quantification of genital human 
immunodeficiency virus type 1 (HIV-1) DNA in specimens from women with low plasma HIV-1 RNA levels typical of HIV-1 nontransmitters. J Clin Microbiol 2006, 44:4357-4362.

15. Rousseau CM, Nduati RW, Richardson BA, John-Stewart GC, MboriNgacha DA, Kreiss JK, Overbaugh J: Association of levels of HIV-1-infected breast milk cells and risk of mother-to-child transmission. J Infect Dis 2004, 190:1880-1888.

16. Clouse KA, Powell D, Washington I, Poli G, Strebel K, Farrar W, Barstad P, Kovacs J, Fauci AS, Folks TM: Monokine regulation of human immunodeficiency virus-1 expression in a chronically infected human $T$ cell clone. J Immunol 1989, 142:431-438.

17. Folks TM, Clouse KA, Justement J, Rabson A, Duh E, Kehrl JH, Fauci AS: Tumor necrosis factor alpha induces expression of human immunodeficiency virus in a chronically infected T-cell clone. Proc Natl Acad Sci USA 1989, 86:2365-2368.

18. John-Stewart GC, Mbori-Ngacha D, Payne BL, Farquhar C, Richardson BA, Emery S, Otieno P, Obimbo E, Dong T, Slyker J, et al: HV-1-specific cytotoxic T lymphocytes and breast milk HIV-1 transmission. J Infect Dis 2009, 199:889-898

19. Neilson JR, John GC, Carr JK, Lewis $P$, Kreiss JK, Jackson S, Nduati RW, Mbori-Ngacha D, Panteleeff DD, Bodrug S, Giachetti C, et al: Subtypes of human immunodeficiency virus type 1 and disease stage among women in Nairobi, Kenya. J Virol 1999, 73:4393-403.

20. Tetali S, Abrams E, Bakshi S, Paul M, Oyaizu N, Pahwa S: Virus load as a marder of disease progression in children. AIDS Research and Human Retroviruses 1996, 12:669-675.

21. Beck IA, Drennan KD, Melvin AJ, Mohan Km, Herz Am, Alarcón J, Piscoya J, Velázquez C, Frenkel M: Simple, sensitive, and specific detection of human immunodeficiency virus type 1 subtype B DNA in dried blood samples for diagnosis in infants in the field. J Clin Microbiol 2001, 39:29-33.

\section{Pre-publication history}

The pre-publication history for this paper can be accessed here: http://www.biomedcentral.com/1471-2431/11/18/prepub

\section{doi:10.1186/1471-2431-11-18}

Cite this article as: Chohan et al: Evaluation of a single round polymerase chain reaction assay using dried blood spots for diagnosis of HIV-1 infection in infants in an African setting. BMC Pediatrics 2011 11:18.

\section{Submit your next manuscript to BioMed Central and take full advantage of:}

- Convenient online submission

- Thorough peer review

- No space constraints or color figure charges

- Immediate publication on acceptance

- Inclusion in PubMed, CAS, Scopus and Google Scholar

- Research which is freely available for redistribution 